\title{
Removal Efficiency of Acid Red 18 Dye from Aqueous Solution Using Different Aluminium-Based Electrode Materials by Electrocoagulation Process
}

\author{
Nurulhuda Amri ${ }^{1,2}$, Ahmad Zuhairi Abdullah ${ }^{1, *}$, and Suzylawati Ismail ${ }^{1}$ \\ ${ }^{1}$ School of Chemical Engineering, Universiti Sains Malaysia, Engineering Campus, 14300 Nibong Tebal, Penang, Malaysia \\ ${ }^{2}$ Faculty of Chemical Engineering, Universiti Teknologi MARA (UiTM), Cawangan Pulau Pinang, 13500 Permatang Pauh, \\ Penang, Malaysia
}

* Corresponding author:

tel: +604-5996411

email: chzuhairi@usm.my

Received: January 31, 2019

Accepted: May 7, 2019

DOI: $10.22146 / \mathrm{ijc} .43206$

\begin{abstract}
This work compares commercial aluminium electrode for use in the treatment of wastewater by electrocoagulation process against waste aluminium cans electrode. The applicability of the waste aluminium cans electrode was tested for decolorization of Acid Red 18 dye as a model pollutant. The batch electrocoagulation process using both types of electrode was conducted at a current density of $25 \mathrm{~mA} / \mathrm{cm}^{2}$, a $\mathrm{pH}$ of 3, an initial concentration of $100 \mathrm{mg} / \mathrm{L}$ and $25 \mathrm{~min}$ of reaction time. The elemental composition and surface morphology of both electrode materials and the sludge produced were analyzed using SEM-EDX to establish the correlation between the properties and characteristics of both electrode materials with their dye removal performance. The results demonstrated that waste aluminium cans performed better than commercial aluminium electrode with a removal efficiency of $100 \%$ in 25 min of reaction time. This was due to the higher Al dissolution of waste aluminium cans electrode that contributed to the larger amount of $\mathrm{Al}^{3+}$ released into the solution to consequently form more flocs to remove the dye molecules. In conclusion, the proposed waste aluminium electrode was considered as efficient and cost-effective and had the potential to replace the conventional ones in treating colored industrial wastewater using electrocoagulation process.
\end{abstract}

Keywords: waste aluminium cans; commercial aluminium electrode; electrocoagulation process; Acid Red 18; removal efficiency

\section{- INTRODUCTION}

Large amounts of disposed aluminium can contribute to solid wastes either in the form of industrial or domestic waste; they originate from products such as cans, food trays, pie plates, frozen foods containers, wrapping foil, etc. [1]. Annually, 1.5 million tons of waste is created worldwide by throwing away aluminium cans that not only fill up the landfills, but also cause wastage in energy and extensive environmental damage in creating new cans [2]. Recently, the attention of many researchers has shifted towards utilization of waste aluminium cans as a raw material in the preparation of catalysts [3] and nanomaterials [4]. The exploitation of this waste as a raw material in new research fields will present several environmental and economic benefits over a long-term period that will reduce the impact of aluminium wastes by converting them into valuable materials [5].

Aluminium $(\mathrm{Al})$ is one of the electrode materials that has been extensively used, as this type of material presents high electro-dissolution rate and is effective in treating various pollutants using electrocoagulation (EC) process [6-8]. EC process is known as a potential technique for treating industrial effluent due to its simplicity in the design and operation, high efficiency, cost-effective treatment system, and environmental compatibility [9-10]. This process takes the benefits of the binding effect of charge neutralization/surface complexation/adsorption of pollutant onto the in-situ formation of metal hydroxide from the oxidation of sacrificial anode [11]. There have been numerous studies reported on the efficient performance of aluminium 
electrodes used in the EC process for treatment of wastewater containing textile dyes [12-13].

Azo dyes are the largest group of dyes used in the textile industry that represent about $50 \%$ of all the commercial dyes available [10]. They generally have an azo group band $(-\mathrm{N}=\mathrm{N}-)$ together with other chromospheres which are responsible for their intense color, high water solubility, and resistance to degradation under common biological treatment [9]. Acid Red 18 (AR18) dye is one of the dyes under the azo group that is commonly used during the dyeing process. The major environmental problem associated with the use of these dyes is their loss in the dyeing process. It is estimated that around $10-50 \%$ of these dyes are usually lost in the effluent [14]. Wastewaters containing dyes can cause aesthetic problems due to the color even at low concentration, and their intermediate products could be either toxic, carcinogenic, or mutagenic to aquatic life [14-15]. Therefore, the treatment of effluents containing azo dyes is crucial to minimize their harmful impacts on human beings and aquatic life.

Various treatment technologies, including physical, chemical, and biological methods, have been used for the treatment of textile effluents [16]. However, these treatment methods still have certain limitations such as high capital and operation cost, generation of a large amount of sludge and may not be effective for all types of dyes. In Malaysia, conventional wastewater treatment systems that are most commonly applied in textile industries are biological treatment alone or physicochemical treatments followed by a biological treatment [17]. Single conventional biological treatment does not always treat the textile effluent satisfactory as most of the dyes, especially azo dyes [18] are hardly biodegradable at high concentration [13]. Thus, certain pre-treatment, such as physical or chemical process is necessary. In this respect, the EC process can be a good alternative pre-treatment method for biological treatment system due to its advantages.

In this study, waste aluminium cans (WAC) were utilized as a potential electrode for the removal of AR18 dye using an EC process. To the best of our knowledge, no study has been reported on the utilization of this waste material as an electrode in the EC process for the treatment of water or wastewater. Most of the studies available in literature utilized directly commercial electrode materials to evaluate their performance in the EC process [8-10].

Thus, this study aimed to evaluate the applicability of WAC as an electrode and compare the removal performance between the WAC and commercial aluminium (COM) electrode in the decolorization of $\mathrm{AR} 18$ dye via the $\mathrm{EC}$ process. The $\mathrm{Al}$ ion $\left(\mathrm{Al}^{3+}\right)$ contents remaining in the solution after the EC process using both types of electrode material were also analyzed to ensure that the quality of treated water could achieve the permissible limit for industrial effluent discharged [19]. The characteristics of both electrodes in terms of elemental composition, the surface morphology of the electrodes before and after the EC process as well as the sludge produced were also examined to establish the correlation with the dye removal efficiency.

\section{- EXPERIMENTAL SECTION}

\section{Materials}

All chemicals used in this study such as AR18 dye (> 99\% purity), hydrochloric acid $(\mathrm{HCl})$, sodium hydroxide $(\mathrm{NaOH})$ and sodium chloride $(\mathrm{NaCl})$ were of analytical grade and purchased from Merck. Table 1 shows the general properties of the AR18 dye. A stock solution of AR18 dye was prepared by dissolving $1 \mathrm{~g}$ of dye

Table 1. Properties of AR18 dye

\begin{tabular}{ccccc}
\hline Dye & Molecular formula & Molecular weight $(\mathrm{g} / \mathrm{mol})$ & $\lambda_{\max }{ }^{*}(\mathrm{~nm})$ \\
\hline Acid Red 18 & & & \\
\end{tabular}

${ }^{\star} \lambda_{\max }$ is the maximum absorbance of AR18 dye 
in $1 \mathrm{~L}$ of deionized water. Then, the solution was diluted to give the initial concentration of $100 \mathrm{mg} / \mathrm{L}$. The electrical conductivity of the solution was increased by the addition of $2 \mathrm{~g} / \mathrm{L}$ of $\mathrm{NaCl}$ into the solution. Meanwhile, the $\mathrm{pH}$ of the solution was adjusted from the original $\mathrm{pH}$ of 6.8 to 3.0 using $0.1 \mathrm{M} \mathrm{HCl}$ solution.

The COM and WAC were used as materials for electrodes. The COM electrodes were purchased from Neilement Engineering Resources \& Services. The dimensions of the COM electrode are illustrated in Fig. 1. Meanwhile, the WAC was collected from cafeterias in Universiti Sains Malaysia. The WAC was cut into dimensions similar to those of COM electrode but with a different thickness of $0.01 \mathrm{~cm}$ (original thickness of WAC). They were then subjected to a pre-treatment with sandpaper to remove the paint and epoxy coating on the outer and inner walls of the can, and rinsed with deionized water. Finally, the WAC was dried in an oven at $60^{\circ} \mathrm{C}$ and ready to be used in the batch EC experiment.

\section{Instrumentation}

The solution $\mathrm{pH}$ was measured using a $\mathrm{pH}$ meter (Eutech pH2700, Thermo Scientific, Singapore). The concentration of AR18 dye solution was determined using a double beam UV-visible spectrophotometer (Shimadzu 1800, Japan) at a wavelength of $507 \mathrm{~nm}$. The surface morphology and the elemental composition of both electrode materials and sludge produced after the EC process were examined using a scanning electron microscope (SEM) equipped with an energy-dispersive Xray spectroscopy (EDX) facility (Quanta 450 FEG, FEI, Netherlands) operated at an accelerating voltage of $5 \mathrm{kV}$. The concentrations of $\mathrm{Al}^{3+}$ in the treated water were examined using an inductively coupled plasma-optical emission spectrometer (ICP-OES) (ICAP 7600, Thermo Scientific, USA).

\section{Procedure}

Batch monopolar EC experiments were carried out in a 1.1 L rectangular reactor, as shown in Fig. 2. Two pieces of flat WAC and COM plates were used as electrodes, and the distance between the electrodes was set at $0.5 \mathrm{~cm}$. The area of each electrode dipped into the solution for both

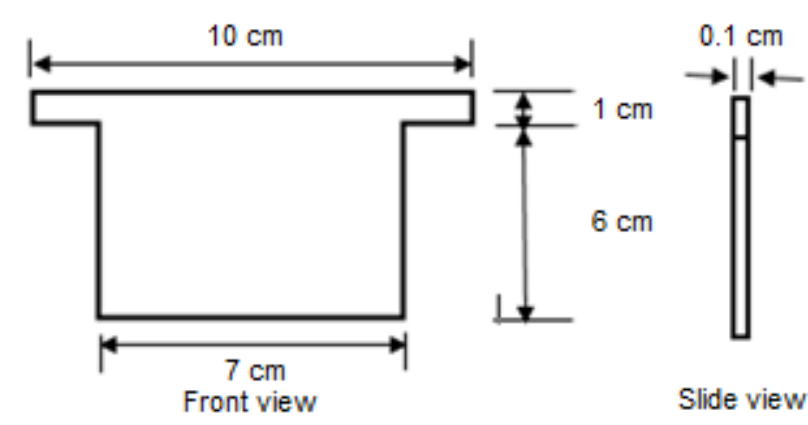

Fig 1. The specific dimensions of a COM electrode

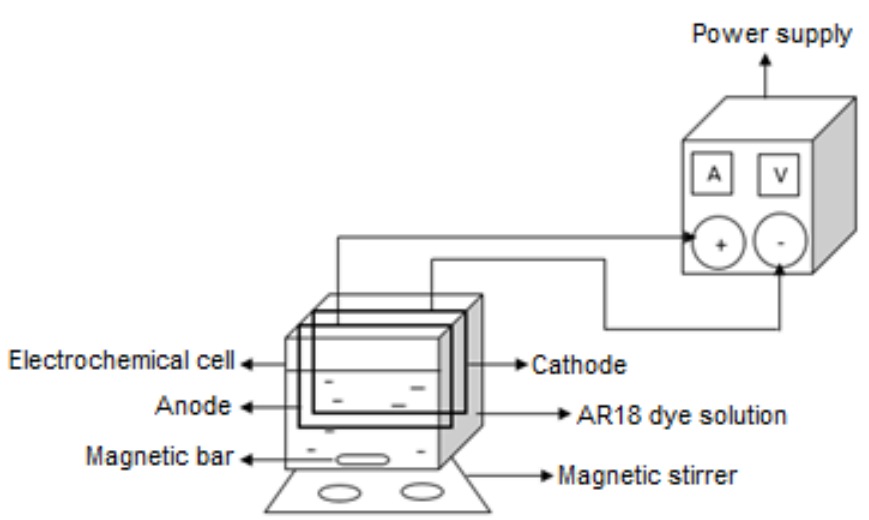

Fig 2. Schematic diagram of the experimental set-up for the EC system

WAC and COM was $6 \mathrm{~cm} \times 7 \mathrm{~cm}$. The electrodes were connected to a DC Power supply (Dazheng PS-305D, $0-5 \mathrm{~A}, 0-30 \mathrm{~V}$ ) to supply and control the required current during the experiment. The water sample $(800 \mathrm{~mL})$ was initially fed into the EC cell, and the current density was set at $25 \mathrm{~mA} / \mathrm{cm}^{2}$ for $25 \mathrm{~min}$. The solution was continuously stirred at $250 \mathrm{rpm}$ during the experiment in order to get a homogeneous solution. All EC experiments for WAC and COM were operated at the best-operating conditions (current density of $25 \mathrm{~mA} / \mathrm{cm}^{2}, \mathrm{pH}$ of 3 , initial concentration of $100 \mathrm{mg} / \mathrm{L}$, electrode distance of $0.5 \mathrm{~cm}, \mathrm{NaCl}$ concentration of $2 \mathrm{~g} / \mathrm{L}$ and reaction time of $25 \mathrm{~min}$ ) as obtained previously. In the preliminary work, a series of one-factor-at-a-time experiments for the effects of current density (10$\left.30 \mathrm{~mA} / \mathrm{cm}^{2}\right), \mathrm{pH}(3-9)$, contact time (0-60 min), $\mathrm{NaCl}$ concentration $(2-5 \mathrm{~g} / \mathrm{L})$ and inter-electrode distance $(0.5-2 \mathrm{~cm})$ were conducted using the same batch EC system. However, the effect of operating parameters to obtain the best set of operating conditions is not reported in this paper. 
Samples of the treated wastewater were taken at different times and filtered through a Whatman filter paper no. 1 prior to its color measurement. Each analysis was conducted in triplicate. The AR18 dye removal efficiency is calculated using Eq. (1):

Removal Efficiency $(\%)=\frac{\mathrm{C}_{0}-\mathrm{C}_{\mathrm{t}}}{\mathrm{C}_{0}} \times 100 \%$

where, $\mathrm{C}_{0}$ is the initial dye concentration $(\mathrm{mg} / \mathrm{L})$ and $\mathrm{C}_{\mathrm{t}}$ is dye concentration at a time, $\mathrm{t}(\mathrm{mg} / \mathrm{L})$.

\section{- RESULTS AND DISCUSSION}

\section{Elemental Composition}

The elemental composition of WAC and COM were determined using EDX analysis, and the results are presented in Table 2. From the results, both WAC and COM electrodes were classified as aluminium alloys. Al was the main metal element in both electrode materials that represented about $85.67 \%$ and $79.05 \%$ by weight respectively for WAC and COM. The composition of $\mathrm{Al}$ was found to be higher in WAC than that of COM by about $6.62 \%$ with additional elements of $\mathrm{Mg}$ and $\mathrm{Mn}$. Meanwhile, COM had Fe elemental composition of $0.41 \%$ by weight. The difference in the composition and alloying elements of these materials was believed to be one of the factors that contributed to the difference in the performance of AR18 dye removal in the EC process. Dura and Breslin [8] reported the performance of Al-ZnIn and $\mathrm{Al}-\mathrm{Mg}$ alloy electrodes for the removal of phosphate, $\mathrm{Zn}^{2+}$, and Orange II dye. It was observed that both types of $\mathrm{Al}$ alloy performed well in removing all the pollutants as compared to pure $\mathrm{Al}$ electrode due to their low overpotential values as obtained from the polarization and cyclic polarization experiment. These low overpotential

Table 2. Elemental compositions of WAC and COM electrodes

\begin{tabular}{lcc}
\hline \multirow{2}{*}{ Element } & WAC & COM \\
\cline { 2 - 3 } & Weight (\%) & Weight (\%) \\
\hline $\mathrm{Al}$ & 85.67 & 79.05 \\
$\mathrm{C}$ & 9.60 & 16.54 \\
$\mathrm{O}$ & 2.55 & 3.99 \\
$\mathrm{Mg}$ & 1.16 & - \\
$\mathrm{Mn}$ & 1.02 & - \\
$\mathrm{Fe}$ & - & 0.41 \\
\hline
\end{tabular}

values indicated a higher dissolution behavior of Al alloy than the pure $\mathrm{Al}$ electrode, which was more passive. However, the performance of Al-Zn-In was slightly better than $\mathrm{Al}-\mathrm{Mg}$, attributed to the instability of the passive film that was formed on the Al-Zn-In electrode to significantly enhance the dissolution of the electrode and the production of $\mathrm{Al}^{3+}$ ion.

\section{Removal efficiency of AR18 dye using different electrode materials}

In order to examine the potential of this waste electrode as a green alternative to the commercial $\mathrm{Al}$ electrode, the performance of WAC and COM in the decolorization of AR18 dye was investigated. The effect of different electrode materials on AR18 removal was conducted at the best-operating conditions as mentioned earlier. Fig. 3 illustrates the removal efficiency of AR18 dye and solution $\mathrm{pH}$ for WAC and COM electrodes with time. As can be observed, the removal trend was similar for both electrodes in which the decolorization efficiency increased drastically in the first $5 \mathrm{~min}$ of the reaction with up to $80 \%$ removals owing to higher precipitation rates under the acidic condition. After this point, the removal rates gradually increased, reaching a plateau in the next $20 \mathrm{~min}$ due to the transition of the dye removal mechanism from precipitation to the adsorption process [13]. However, it was found that the WAC performed better as compared to the COM with removal efficiencies of $100.00 \%$ and $87.56 \%$, respectively after $25 \mathrm{~min}$.

This finding was in agreement with the elemental analysis results (Table 2) as one of the $\mathrm{Al}$ alloying elements in WAC was $\mathrm{Mg}$ that could activate and enhance the $\mathrm{Al}$ dissolution through anode oxidation. Higher dissolution of WAC electrode produced a larger amount of $\mathrm{Al}^{3+}$ in the solution and subsequently proceeded through a hydrolysis reaction. This reaction generated various cationic monomeric and polymeric aluminium hydrolysis species. These cationic species were attracted to the negative charge of AR18 dye molecules, to result in the removal by either precipitation or adsorption mechanism. The result was consistent with Dura and Breslin [8]. They observed that the Al-Mg alloy electrode exhibited higher dissolution in 


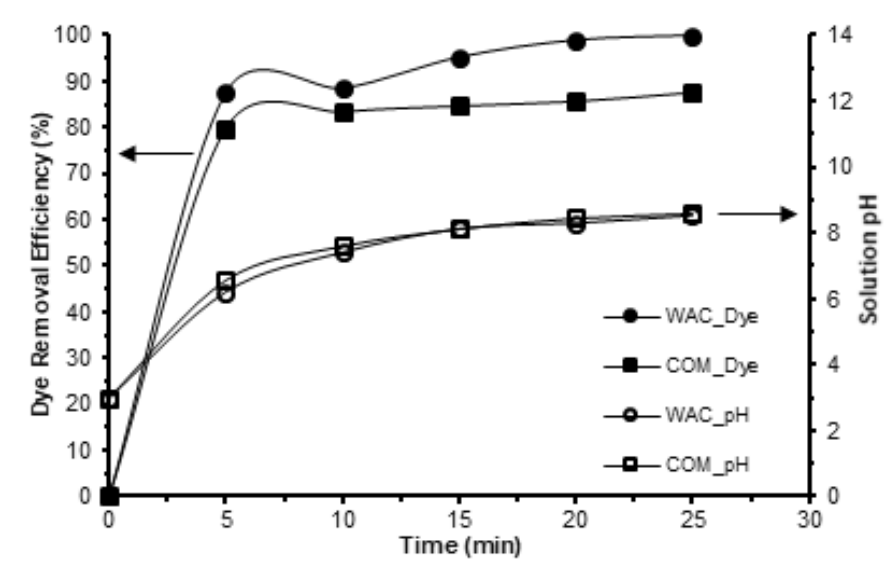

Fig 3. The removal efficiency of AR18 dye and the solution $\mathrm{pH}$ by WAC and COM electrodes

the presence of $\mathrm{NaCl}$ with more than $90 \%$ removal efficiencies of phosphate ions by the EC process.

Initial $\mathrm{pH}$ of the dye solution is also an important parameter affecting the predominance of coagulant species produced during the EC process. Generally, the $\mathrm{pH}$ of the treated water changes during the EC process. As can be seen in Fig. 3, the similar trends of increasing solution $\mathrm{pH}$ throughout the EC treatment were observed for both types of electrode material to indicate that the metal hydroxide species that formed in the solution were identical due to the constant initial solution $\mathrm{pH}$ of 3.0 set for WAC and COM electrodes. Overall, the solution $\mathrm{pH}$ increased rapidly to a maximum of 8.6 in $25 \mathrm{~min}$. During the first $5 \mathrm{~min}$, the initial solution $\mathrm{pH}$ increased drastically from 3.0 to 6.2 and 6.5 for WAC and COM electrodes, respectively. This was attributed to the hydroxyl ion release from water reduction occurring at the cathode during the EC treatment. Meanwhile, the dissolution of anode produced $\mathrm{Al}^{3+}$, as expressed by Eq. (2). In acidic condition, $\mathrm{Al}^{3+}$ can directly undergo spontaneous hydrolysis reactions producing various monomeric species such as $\mathrm{Al}(\mathrm{OH})_{2}{ }^{+}$and $\mathrm{Al}(\mathrm{OH})^{2+}$ which then transform into $\mathrm{Al}(\mathrm{OH})_{3}$ as shown in Eq. (3) to (5). However, the other ionic species $\left(\mathrm{Al}(\mathrm{OH})_{4}^{-}, \mathrm{Al}(\mathrm{OH})^{2+}\right.$, $\left.\mathrm{Al}_{2}(\mathrm{OH})_{2}{ }^{4+}\right)$ and polymeric species $\left(\mathrm{Al}_{6}(\mathrm{OH})_{15}{ }^{3+}\right.$, $\mathrm{AL}_{7}(\mathrm{OH})_{7}^{4+}, \mathrm{Al}_{8}(\mathrm{OH})_{20}{ }^{4+}$, etc. $)$ may also present in the system depending on the $\mathrm{pH}$ of the solution to be finally converted to $\mathrm{Al}(\mathrm{OH})_{3}$ flocs. These $\mathrm{Al}(\mathrm{OH})_{3}$ flocs are beneficial for the adsorption of soluble organic pollutants due to their large surface area. The overall process of flocs formation can be described as [13]:

$$
\begin{aligned}
& \mathrm{Al} \rightarrow \mathrm{Al}^{3+}+3 \mathrm{e}^{-} \\
& \mathrm{Al}^{3+}+\mathrm{H}_{2} \mathrm{O} \rightarrow \mathrm{Al}(\mathrm{OH})_{2}{ }^{+}+\mathrm{H}^{+} \\
& \mathrm{Al}(\mathrm{OH})_{2}^{+}+\mathrm{H}_{2} \mathrm{O} \rightarrow \mathrm{Al}(\mathrm{OH})^{2+}+\mathrm{H}^{+} \\
& \mathrm{Al}(\mathrm{OH})^{2+}+\mathrm{H}_{2} \mathrm{O} \rightarrow \mathrm{Al}(\mathrm{OH})_{3}+\mathrm{H}^{+}
\end{aligned}
$$

The high decolorization efficiencies as demonstrated by both types of electrodes in the first 5 min were mainly due to the dye precipitation process by $\mathrm{Al}^{3+}$ as well as monomeric and polymeric species that formed in the solution at $\mathrm{pH}<6.5$. However, as the $\mathrm{pH}$ was increased exceeding 6.5 , most of the aluminium hydroxide precipitated as $\mathrm{Al}$ coagulant, thus responsible for the adsorption of the remaining dye molecules. The finding in this work was in good agreement that of Khorram et al. [13]. They reported that dye precipitation process was the main mechanism that was responsible for the high removal efficiency followed by the adsorption of the dye polymeric colloidal species by $\mathrm{Al}(\mathrm{OH})_{3}$ flocs which had a lesser effect. Thus, it can be summarized that the dye removal mechanisms for both WAC and COM electrodes were identical as the solution $\mathrm{pH}$ for both types of electrode material were almost the same throughout the EC process.

On the other hand, the finding was also consistent with that reported by Elabbas et al. [20]. They observed that changes in the solution $\mathrm{pH}$ were greatly influenced by the nature of the electrode materials. They found that the increase in the solution $\mathrm{pH}$ with time for aluminium alloy was slightly higher than that of pure aluminium leading to higher removal efficiency of chromium and COD. Since both types of electrode used in this study were categorized as the same nature of electrode material, which was aluminium alloys, they possessed rather similar behavior towards the $\mathrm{pH}$ change during the EC process.

Besides, the excellent removal performance of WAC could also be explained by the higher dissolution of WAC electrodes as compared to COM that was represented by the weight loss of electrodes, as shown in Fig. 4. Higher weight loss of WAC anode electrode 


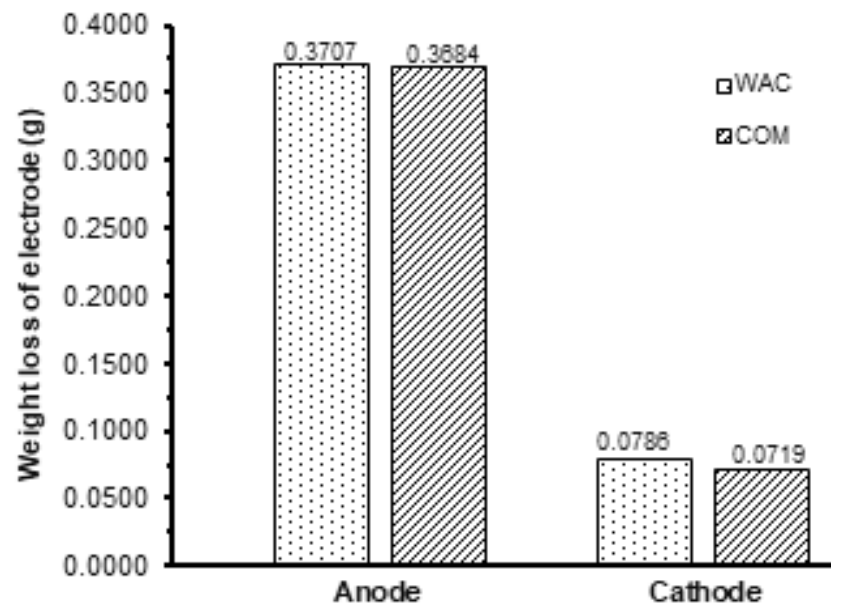

Fig 4. Weight loss of anodes and cathodes after the EC process

contributed to the higher amount of $\mathrm{Al}^{3+}$ released into the solution to destabilize the colloidal particles and form more flocs to remove the dye molecules. Results obtained in this work revealed that WAC was more superior to those reported in the literature. Khosravi et al. [10] reported that the highest AR18 removal of $92.3 \%$ was obtained by $\mathrm{Al}$ electrode at an optimum reaction time of $40 \mathrm{~min}, \mathrm{pH} 4$ and a current density of $26 \mathrm{~mA} / \mathrm{cm}^{2}$. In addition, Azarian et al. [15] observed that the highest AR18 removal of $95.0 \%$ was obtained by $\mathrm{Al}$ electrode under an optimum current density of $1.2 \mathrm{~mA} / \mathrm{cm}^{2}, \mathrm{pH} 7$ and reaction time of $45 \mathrm{~min}$.

The rate of AR18 dye decolorization can also be
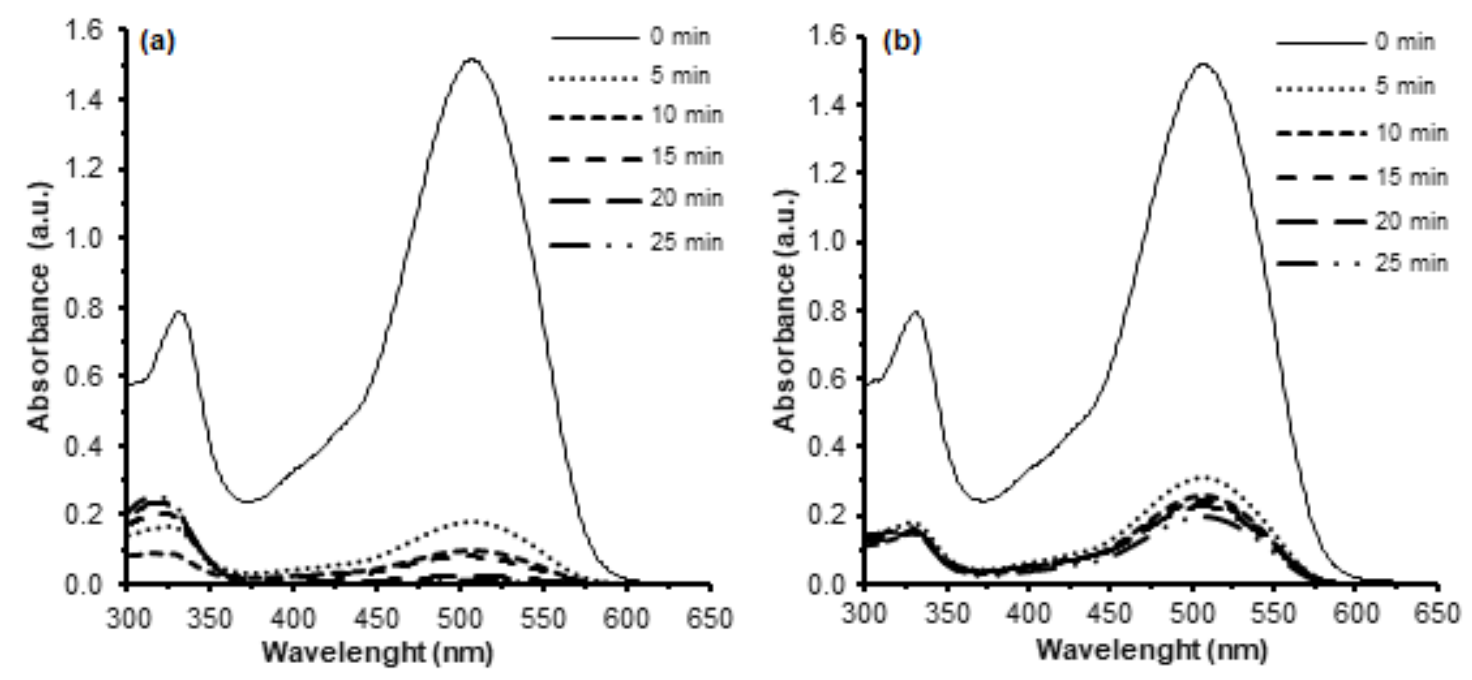

Fig 5. Absorbance spectra of AR18 dye during the EC process at different reaction times using (a) WAC and (b) COM electrodes

Nurulhuda Amri et al.

confirmed by the absorption spectrum, as illustrated in Fig. 5. The absorbance by AR 18 dye can be characterized by two peaks at $507 \mathrm{~nm}$ in the visible region and $320 \mathrm{~nm}$ in the ultraviolet region. As can be seen clearly, the main peak at $507 \mathrm{~nm}$ decreased significantly with time without the appearance of new absorbance peaks for both types of electrode during the EC process. However, the peak for WAC disappears faster than that of COM within 25 min of reaction time. This suggested that the decolorization involved the decomposition of AR18 dye through the breaking of $-\mathrm{N}=\mathrm{N}$ - belonging to the chromophore group. A similar observation was reported by Azarian et al. [15], but the time taken for the $507 \mathrm{~nm}$ peak disappearance was relatively longer, i.e., between 30 to $120 \mathrm{~min}$.

In order to ensure that the EC was a safe process and did not need any further treatment for treating excessive residual $\mathrm{Al}^{3+}$ ions after the process, the treated sample was then examined using ICP-OES. From the results in Table 3, it can be concluded that the residual $\mathrm{Al}^{3+}$

Table 3. The concentrations of $\mathrm{Al}$ ion remaining in the treated water and the acceptable limit for $\mathrm{Al}$ ion from industrial effluent discharge [19]

\begin{tabular}{cc|cc}
\hline $\begin{array}{c}\text { Electrode } \\
\text { material }\end{array}$ & $\begin{array}{c}\text { Treated water } \\
{\left[\mathrm{A} l^{3+}\right](\mathrm{ppm})}\end{array}$ & $\begin{array}{c}\text { Standard A } \\
{\left[\mathrm{Al}^{3+}\right](\mathrm{ppm})}\end{array}$ & $\begin{array}{c}\text { Standard B } \\
{\left[\mathrm{Al}^{3+}\right](\mathrm{ppm})}\end{array}$ \\
\hline WAC & 0.6 & 10 & 15 \\
COM & 2.7 & 10 & 15 \\
\hline
\end{tabular}



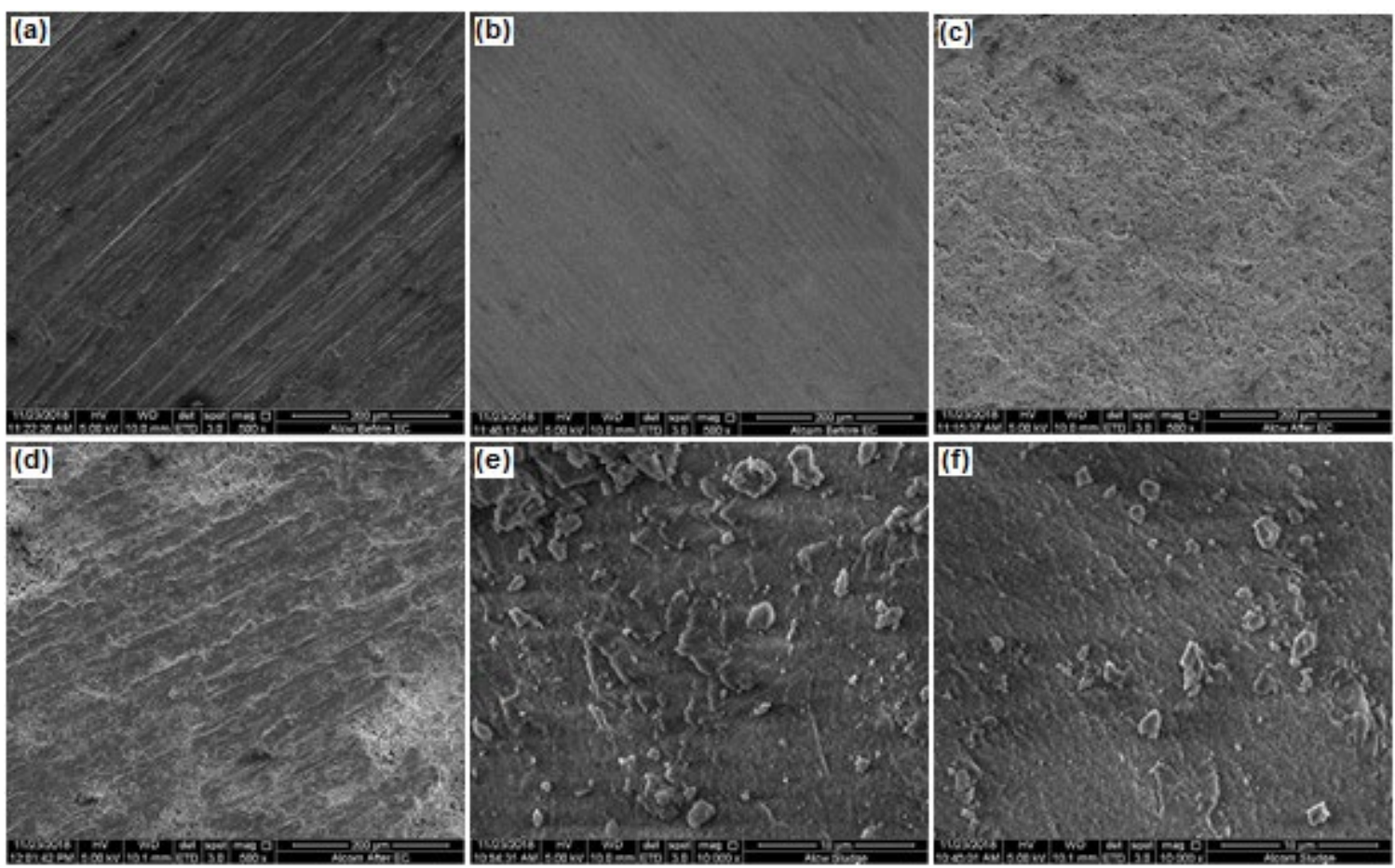

Fig 6. SEM images for (a) WAC before EC (500×), (b) COM before EC (500×), (c) WAC after EC (500×), (d) COM after EC (500×), (e) WAC sludge (10kx), (f) COM sludge (10k $\times$ )

concentrations in treated water using WAC and COM were 0.6 and $2.7 \mathrm{ppm}$, respectively. Thus, this was an additional benefit of the use of waste electrode as the concentration of $\mathrm{Al}^{3+}$ in the treated water was much lower compared to that of COM. This might be due to the fact that most of the $\mathrm{Al}^{3+}$ ions produced from the dissolution of WAC anode effectively combined with hydroxyl ions to form a higher amount of $\mathrm{Al}(\mathrm{OH})_{3}$ flocs that ended up in the WAC sludge as confirmed by the surface morphology and EDX analysis as shown in Fig. 6(e) and $7(\mathrm{a})$, respectively. However, both electrodes still could be considered as harmless electrodes since they showed lower residual $\mathrm{Al}$ concentrations as compared to the permissible limit stated in the Malaysian's Fifth Schedule of Environmental Quality (Industrial Effluent) Regulation 2009 which are 10 ppm for Standard A and 15 ppm for Standard B[19].

\section{Surface Characterization}

Fig. $6(\mathrm{a}-\mathrm{d})$ present the microscopic images of the surface morphology of both electrode materials while those of dried sludges produced after the EC process are shown in Fig. 6(e-f). The images of electrodes before treatment show that the WAC electrode had a relatively rougher surface structure as compared to $\mathrm{COM}$, which features a relatively smooth surface. The rough structure surface of WAC was mainly caused by the pre-treatment of the electrode with sandpaper to remove the paint and epoxy coating on the outer and inner walls of the can. However, both material surfaces changed to rather coarser structures after the EC process. WAC surface presented a well uniform distribution of visible dents generated as a result of higher electrode dissolution.

Meanwhile, a non-uniform distribution of visible dents was observed on the surface of COM. Thus, it can be summarized that the more uniform dissolution of WAC electrodes led to the higher removal of AR18 dye as compared to the non-uniform dissolution of COM electrode. The produced sludge image exhibited similar features for both electrode materials indicating the presence of identical elemental constituents such as $\mathrm{Al}$, $\mathrm{O}, \mathrm{Na}$, and $\mathrm{Cl}$. However, it is observed that the number and size of particles existing in WAC were larger than those of COM sludge suggesting greater formation of 

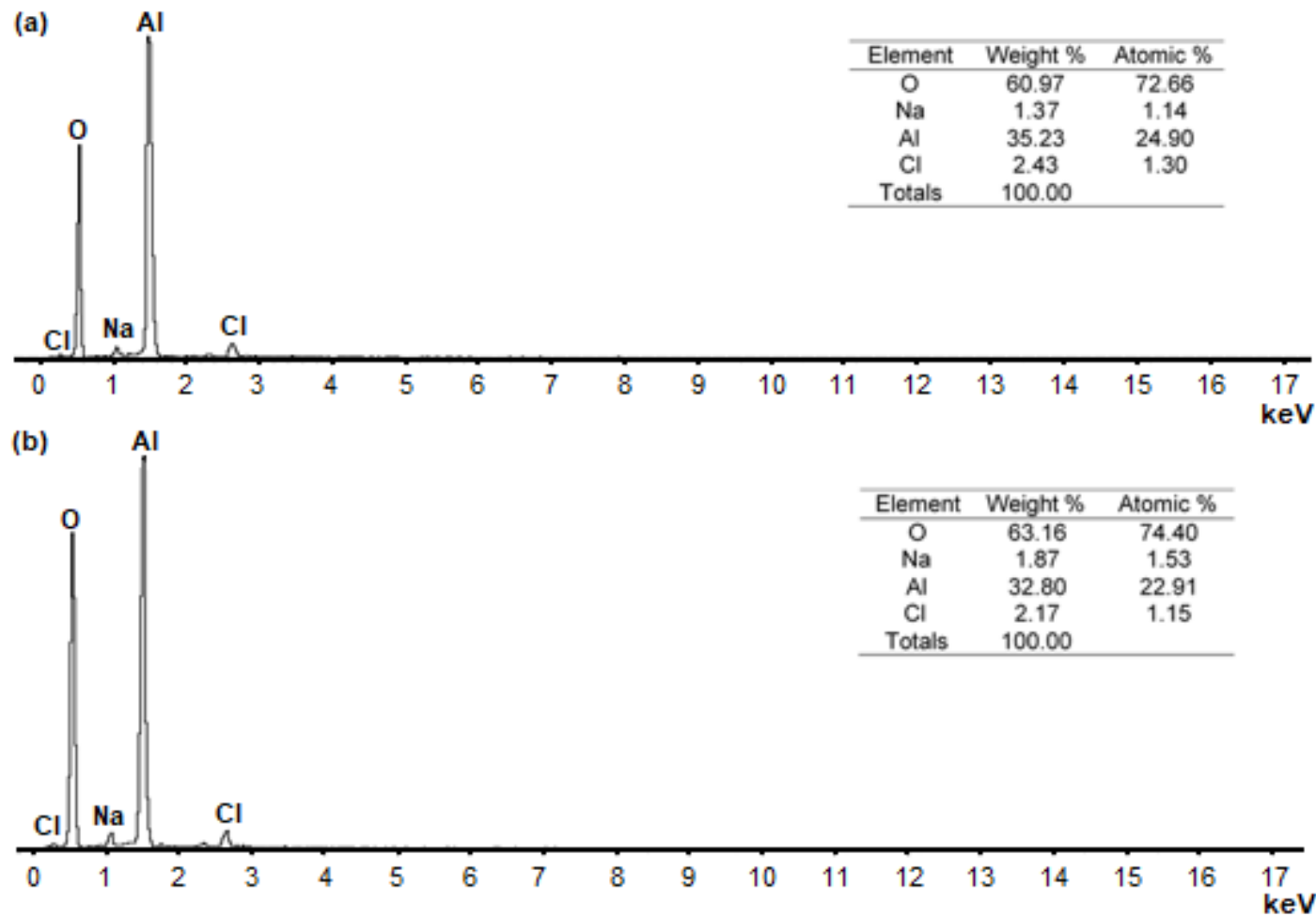

Fig 7. EDX Analysis results of sludge produced after the EC treatment using (a) WAC and (b) COM electrodes

$\mathrm{Al}(\mathrm{OH})_{3}$ flocs in the WAC sludge. This can be confirmed by the EDX analysis results, as shown in Fig. 7(a) and 7(b) where the composition of $\mathrm{Al}$ element (by weight \%) for WAC sludge was higher than COM with a difference of $2.43 \%$. The presence of $\mathrm{Na}$ and $\mathrm{Cl}$ ion was also detected in both types of sludge due to the usage of $\mathrm{NaCl}$ as a supporting electrolyte in the EC process.

\section{- CONCLUSION}

In the present work, the dye removal efficiency and changes in the solution $\mathrm{pH}$ with time as well as the quality of the treated water using WAC and COM electrodes via EC process were studied. The WAC electrode demonstrated better performance than COM electrode as it could decolorize the AR18 dye faster with $100 \%$ removal efficiency in $25 \mathrm{~min}$ and produced lower residual $\mathrm{Al}$ concentration of $0.6 \mathrm{ppm}$ in the treated water after the EC treatment. During the EC process, it was also observed that $\mathrm{pH}$ of the solution increased considerably with both types of electrode materials reaching a maximum of 8.6, indicating that they performed similar dye removal mechanism due to the identical nature of the electrode materials. In summary, the utilization of this material offered several advantages as it could reduce the cost for electrode material that needs to be replaced periodically and at the same time transforming this WAC into a valuable material.

\section{- ACKNOWLEDGMENTS}

The authors gratefully acknowledge the financial support received from the Ministry of Education (MOE) of Malaysia (LRGS Grant) (Project number 67215001) as well as Universiti Teknologi MARA (UiTM) for the study leave of the first author.

\section{- REFERENCES}

[1] Nogueira, F.G.E., Asencios, Y.J.O., Rodella, C.B., Porto, A.L.M., and Assaf, E.M., 2016, Alternative route for the synthesis of high surface-area $\eta$ $\mathrm{Al}_{2} \mathrm{O}_{3} / \mathrm{Nb}_{2} \mathrm{O}_{5}$ catalyst from aluminum waste, Mater. Chem. Phys., 184, 23-30.

[2] Marck Industries, Facts about Recycling Aluminum, 2015, https://www.marck.net/facts-about-recyclingaluminum/, accessed on 10 December 2018. 
[3] Abdelrahman, E.A., 2018, Synthesis of zeolite nanostructures from waste aluminum cans for efficient removal of malachite green dye from aqueous media, J. Mol. Liq., 253, 72-82.

[4] Ahmedzeki, N.S., Hussein, S.J., and Abdulnabi, W.A., 2018, Synthesis of nano crystalline gamma alumina from waste cans, Iraqi J. Chem. Pet. Eng., 19 (1), 45-49.

[5] Hu, Y., Bakker, M.C.M., and de Heij, P.G., 2011, Recovery and distribution of incinerated aluminum packaging waste, Waste Manage., 31 (12), 2422-2430.

[6] Simanjuntak, W., Ginting, I., and Pandiangan, K.D., 2011, Removal of natural organic matter using electrocoagulation as a first step for desalination of brackish water, Indones. J. Chem., 11 (1), 103-107.

[7] Ensano, B.M.B., Borea, L., Naddeo, V., Belgiorno, V., de Luna, M.D.G., Balakrishnan, M., and Ballesteros, F.C., 2019, Applicability of the electrocoagulation process in treating real municipal wastewater containing pharmaceutical active compounds, $J$. Hazard. Mater., 361, 367-373.

[8] Dura, A., and Breslin, C.B., 2019, Electrocoagulation using aluminium anodes activated with $\mathrm{Mg}$, In and Zn alloying elements, J. Hazard. Mater., 366, 39-45.

[9] Ghalwa, N.M.A., Saqer, A.M., and Farhat, N.B., 2016, Removal of Reactive Red 24 dye by clean electrocoagulation process using iron and aluminum electrodes, J. Chem. Eng. Process Technol., 7 (1), 1-7.

[10] Khosravi, R., Hazrati, S., and Fazlzadeh, M., 2016, Decolorization of AR18 dye solution by electrocoagulation: Sludge production and electrode loss in different current densities, Desalin. Water Treat., 57 (31), 14656-14664.

[11] Zhang, X.D., Hao, J.D., Li, W.S., Jin, H.J., Yang, J., Huang, Q.M., Lu, D.S., and Xu, H.K., 2009, Synergistic effect in treatment of C.I. Acid Red 2 by electrocoagulation and electrooxidation, J. Hazard. Mater., 170 (2-3), 883-887.

[12] El-Ashtoukhy, E.S.Z., and Amin, N.K., 2010, Removal of acid green dye 50 from wastewater by anodic oxidation and electrocoagulation-A comparative study, J. Hazard. Mater., 179 (1-3), 113-119.

[13] Khorram, A.G., and Fallah, N., 2018, Treatment of textile dyeing factory wastewater by electrocoagulation with low sludge settling time: Optimization of operating parameters by RSM, $J$. Environ. Chem. Eng., 6 (1), 635-642.

[14] Khandegar, V., and Saroha, A.K., 2013, Electro coagulation for the treatment of textile industry effluent-A review, J. Environ. Manage., 128, 949-963.

[15] Azarian, G., Nematollahi, D., Rahmani, A.R., Godini, K., Bazdar, M., and Zolghadrnasab, H., 2014, Monopolar electro-coagulation process for azo dye C.I. Acid Red 18 removal from aqueous solutions, Avicenna J Environ. Health Eng., 1 (1), e354.

[16] Fajriati, I., Mudasir, and Wahyuni, E.T., 2019, Adsorption and photodegradation of cationic and anionic dyes by $\mathrm{TiO}_{2}$-chitosan nanocomposite, Indones. J. Chem., 19 (2), 441-453.

[17] Pang, Y.L., and Abdullah, A.Z., 2013, Current status of textile industry wastewater management and research progress in Malaysia: A review, Clean-Soil Air Water, 41, 751-764.

[18] Baban, A., Yediler, A., Avaz, G., and Hostede, S.S., 2010, Biological and oxidative treatment of cotton textile dye-bath effluents by fixed and fluidized bed reactors, Bioresour. Technol., 101 (4), 1147-1152.

[19] Ministry of Natural Resources and Environment Malaysia, 2010, Environmental Requirements: A Guide for Investors, $11^{\text {th }}$ Ed., http://www.doe.gov.my/ eia/wp-content/uploads/2012/03/A-Guide-For-Inves tors1.pdf, accessed on 10 December 2018.

[20] Elabbas, S., Ouazzani, N., Mandi, L., Berrekhis, F., Perdicakis, M., Pontvianne, S., Pons, M.N., Lapicque, F., and Leclerc, J.P., 2016, Treatment of highly concentrated tannery wastewater using electrocoagulation: Influence of the quality of aluminium used for the electrode, J. Hazard. Mater., 319, 69-77. 